\title{
AC 2010-1011: DEVELOPMENT OF A SAMPLE TUTORIAL FOR METAL FORMING USING ADVANCED COMPUTER AIDED ENGINEERING TOOLS
}

Raghu Echempati, Kettering University

Andy Fox, Kettering University 


\title{
A SAMPLE TUTORIAL FOR SHEET METAL FORMING ANALYSIS USING ADVANCED COMPUTER AIDED ENGINEERING TOOLS
}

\begin{abstract}
In this paper, a sample tutorial has been developed using advanced CAE tools like HyperWorks and LS-Dyna. The work outlined in this paper is routinely carried by experienced engineers in an industry environment. However, it is believed that the tutorial presented here is believed to be unique in an educational setup. Although many CAE software offer online tutorials relevant to the use of that specific software, there are very few if any that offer help sheets that require a user to switch between different software for carrying out the numerical simulations. A senior level course on metal forming simulation requires the use of various CAE tools to do solid modeling and to carry out the finite element modeling and analysis.
\end{abstract}

An assessment to measure the effectiveness of the use of this tutorial is yet to be fully developed, but it appears based on preliminary survey that the students seem to have appreciated the ease with which the simulations can be carried out based on this tutorial. Also due to an increased demand for trained engineers in the metal forming area such tutorials are very helpful as a first step. A step by step procedure has been written that integrates the use of different CAE tools for metal forming simulation of an example instrument panel (IP) used in automotive applications. As a first step, solid modeling of the individual sheet metal component using different CAD programs like Unigraphics is discussed. A discussion on how these solid models can be imported to different CAE programs to be meshed and then subsequently used in high-end solvers like HyperForm and LSDyna is then presented.

The analyses that were conducted for this tutorial included formability of the individual component. Design of Experiments used in this study is also briefly discussed. The main purpose of doing these types of analyses is to choose the optimum design based on the set constraints. The DOE studies presented in this paper can be adapted in an educational environment. DOE was done to determine the effects that the input factors have on the results of the forming simulations that were conducted. This integrated study can be used in a senior manufacturing simulation course. Finally, the results of this study are discussed and recommendations for future work presented.

\section{Introduction}

In this paper, a sample tutorial for a metal forming simulation using HyperForm (one-step solver) of HyperWorks is presented and discussed. Other tutorials based on using the large deformation nonlinear finite element code - LS-Dyna (incremental solver) has also been developed. The results from both of these software programs are compared for consistency and validation purposes. Due to space limitations only a sample tutorial based on HyperForm is presented below. Students' feedback indicates that the developed tutorial is very useful for their easy understanding of both meshing and analysis of large deformation metal stamping analysis. 


\section{Modeling, Meshing, and Simulating a Bracket Used in an Instrument Panel using (UGS NX 5.0 / HyperMesh 9.0 / HyperForm 9.0) ${ }^{1,2}$}

This tutorial creates and analyzes a sheet metal stamped part that is used to hold a steering column onto an instrument panel shown below. A solid model of the part is created using UGS NX 5.0 and then is meshed using HyperMesh 9.0. A stamping simulation is then performed using HyperForm. A DOE is conducted on the results of the simulation and a brief description is provided.

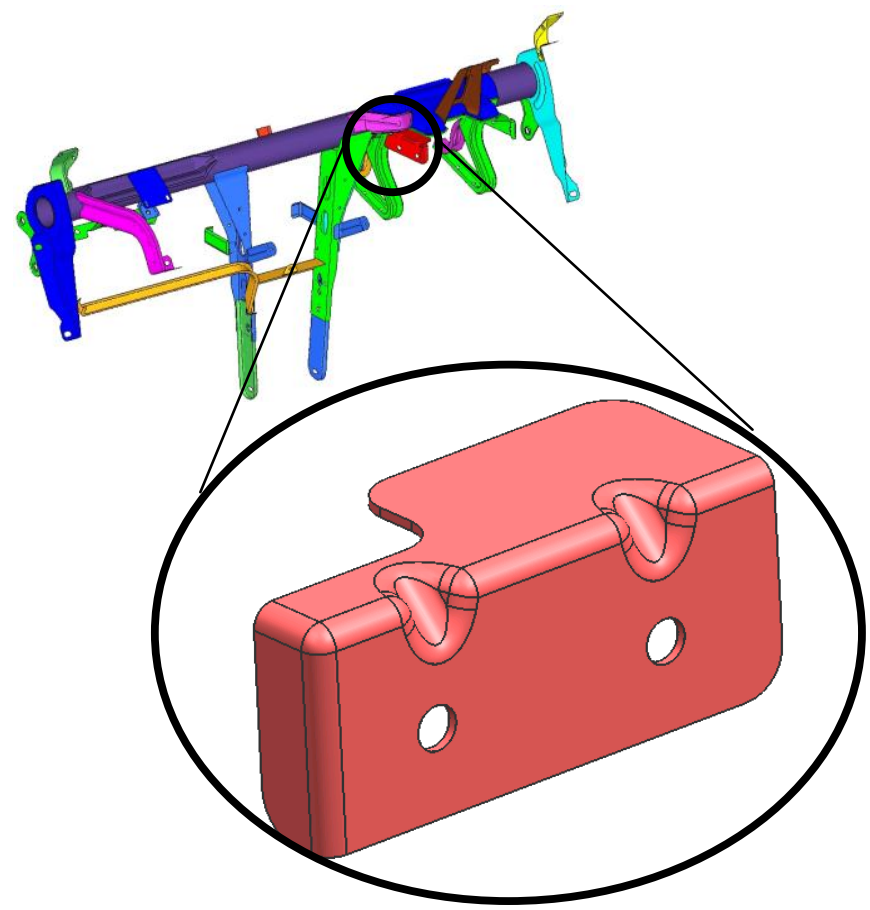

Solid Modeling

1. Open NX 5.0 - Open the CAD program NX 5.0 by going to the Start button in the lower left corner of the screen then All Programs then UGS NX 5.0 then NX 5.0

2. Create a .prt File - Go to File then New then in the File New window that pops up make sure Model is highlighted under the Templates section and then in the New File Name section name it something and save it somewhere you will remember and then click OK.
Figure 1 - Component used in the analysis

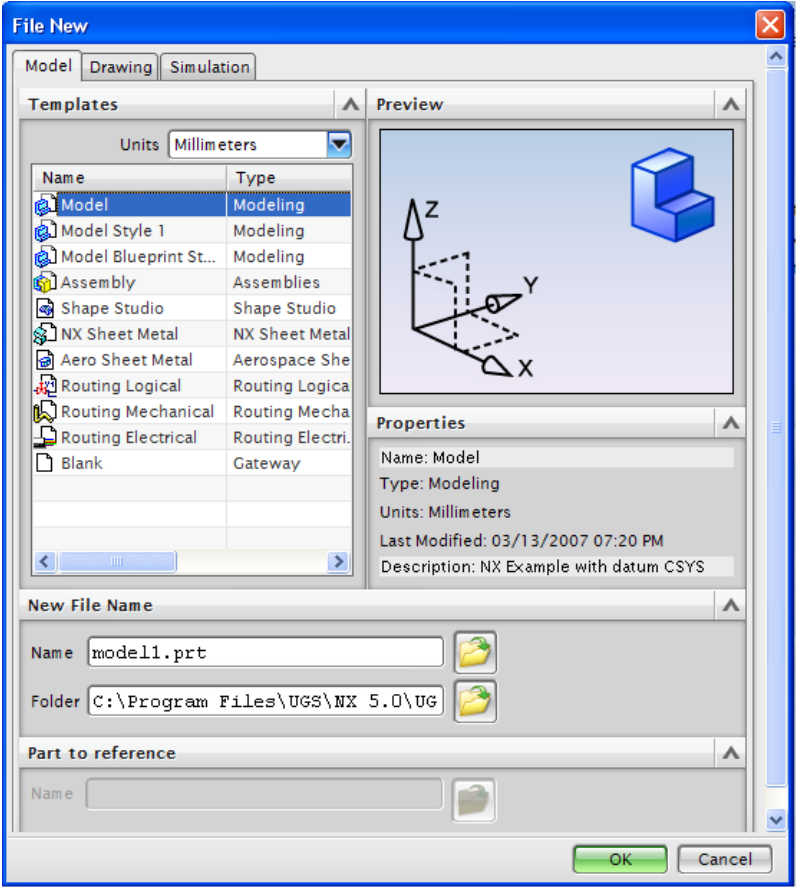

Figure 2 - Name and save the model file using this window 
3. Create the Initial Block - Right click on an area in the top portion of the screen and toggle on the Feature toolbar. Click on the Block icon. If the Block icon isn't showing click the drop down arrow on the right side of the Feature toolbar shown here

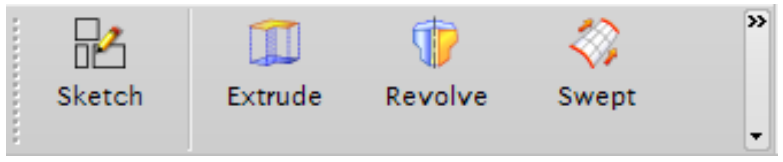

Figure 3 - Feature toolbar

then mouse over Add or Remove Buttons then Feature then click the Block icon then click the drop down arrow again and then click the Block icon.

In the Block window that pops up type in the following values then click on the point at the intersection of the three axes shown then click $\mathbf{O K}$

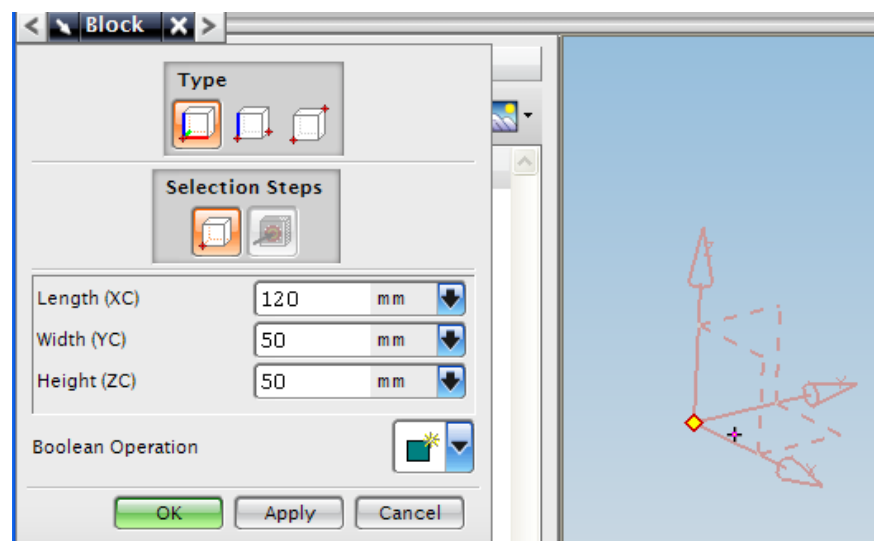

Figure 4 - Coordinate axes

4. Create Two Darts - From the Feature toolbar click on the Dart icon. If the Dart icon is not showing it can be toggled on the same way the Block icon was above.

Type in the following values shown below in the Dart window then click the face on the block that is in the XZ plane (shown as the purple face below) then click the middle mouse button to accept this face, then click the top face then move the slider (currently shown as grey out here) to a position of around 25 then click $\mathbf{O K}$.

Repeat step 4 to add another dart but after clicking the top face you need to click the middle mouse button to accept the second face then click the green edge that shows up and then move the slider so that the dart is in a similar position as shown below then click OK.

Figure 5 - Top Face of box

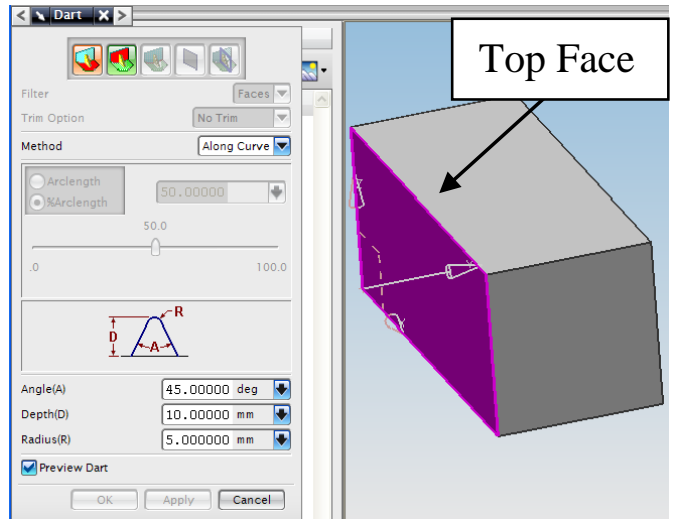




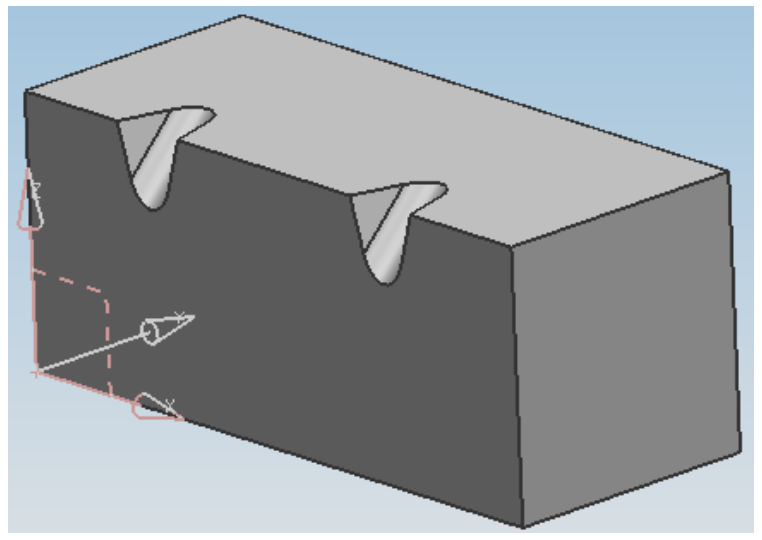

Figure $6-$ Box with darts added

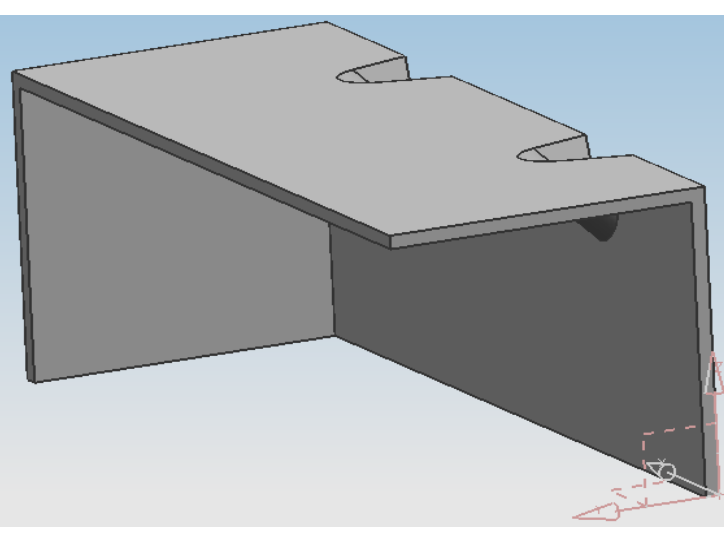

Figure 7 - Box hollowed out

5. Create a Shell - Right click somewhere on the top of the screen and toggle on the Feature Operation toolbar. Click the Shell icon. If the Shell icon is not showing it can be toggled on by click the drop down arrow on the right side of the Feature Operation toolbar. Type in $\mathbf{2 . 2}$ for the Thickness and then click faces to remove them so that the box looks like the picture below then click $\mathbf{O K}$.

6. Smooth the Edges On the Outside - Click the Edge Blend icon from the Feature Operation toolbar and type in $\mathbf{5 . 0}$ for Radius $\mathbf{1}$ then click the edges shown here then click OK. (Although only a couple edges of the darts are selected, the complete perimeter of the dart is automatically smoothed out)

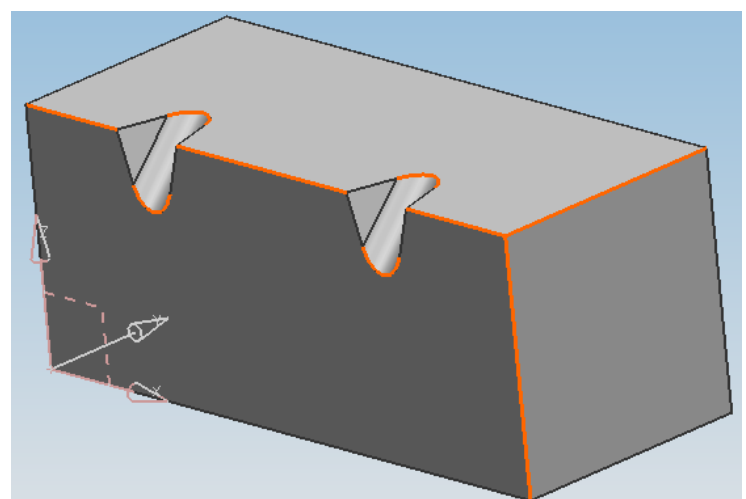

Figure 8 - Edges that need to be selected

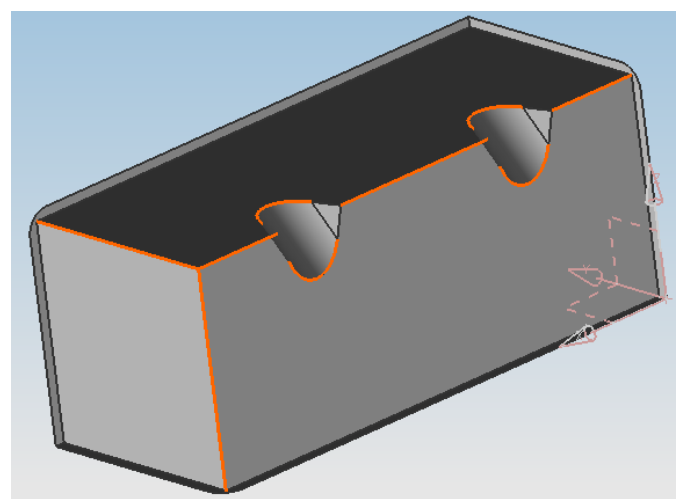

Figure 9 - Edges that need to be selected

7. Smooth the Edges On the Inside - Click the Edge Blend icon again and type in $\mathbf{2 . 8}$ for Radius 1 then click the edges shown here then click $\mathbf{O K}$.

The part should now look like the picture shown in Figure 10. 


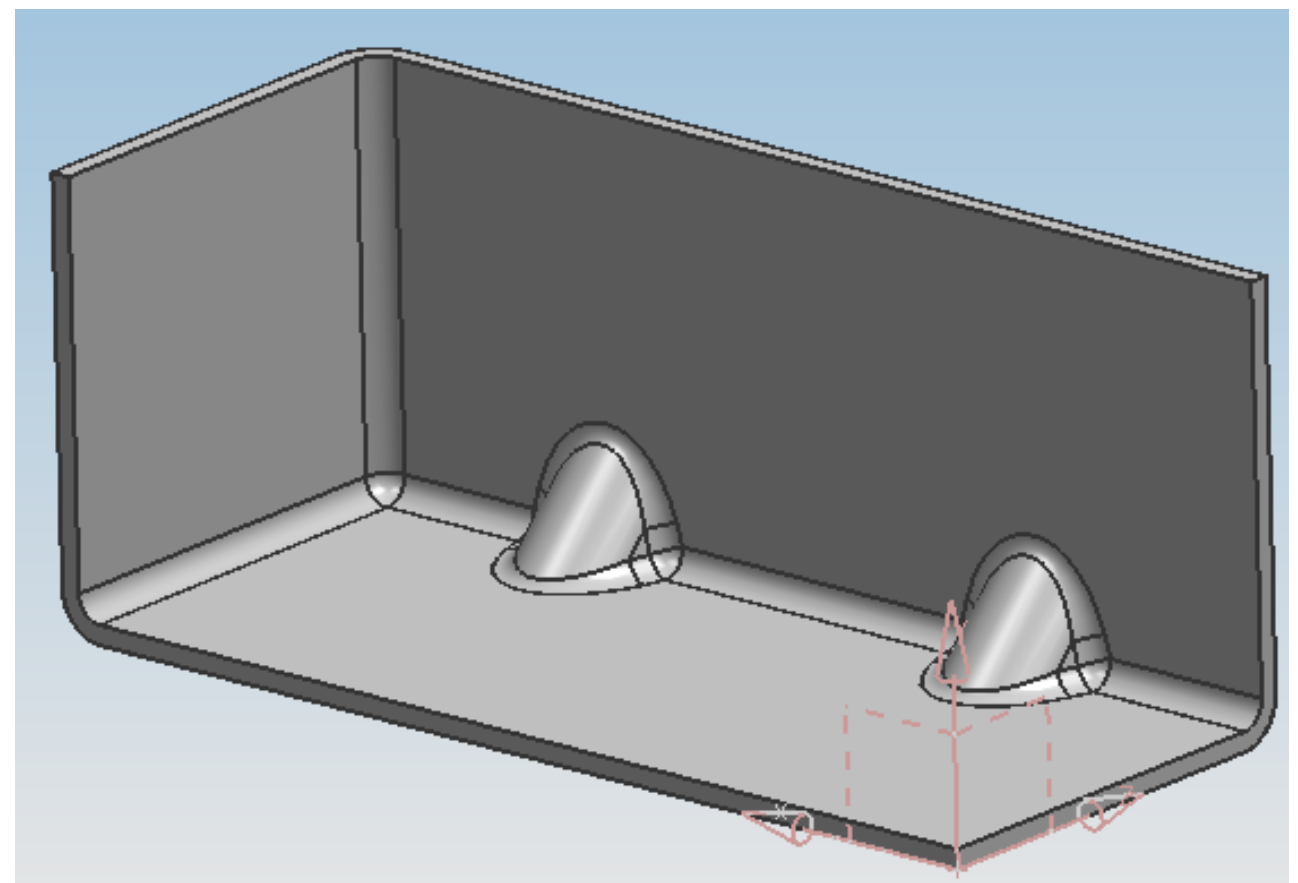

Figure 10 - Correct shape of part

8. Create Two Holes - Go to Insert then Design Feature then Hole. Enter 10 for the Diameter then click the top surface of the part then click the bottom surface of the part to specify the thru face and then click Apply.

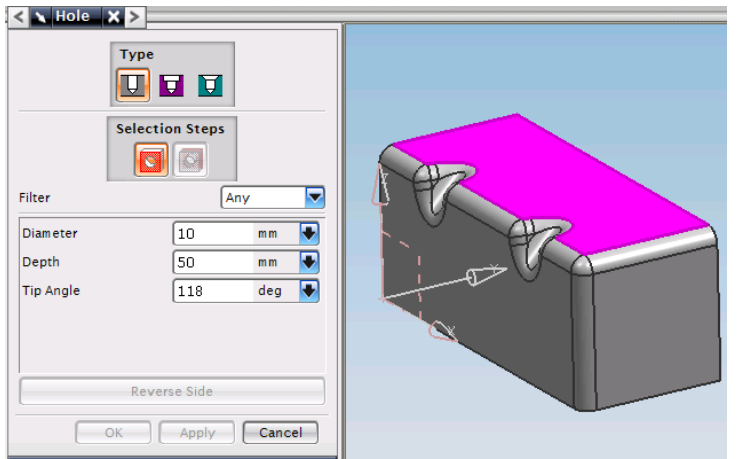

Figure 11 - Surface to create holes in

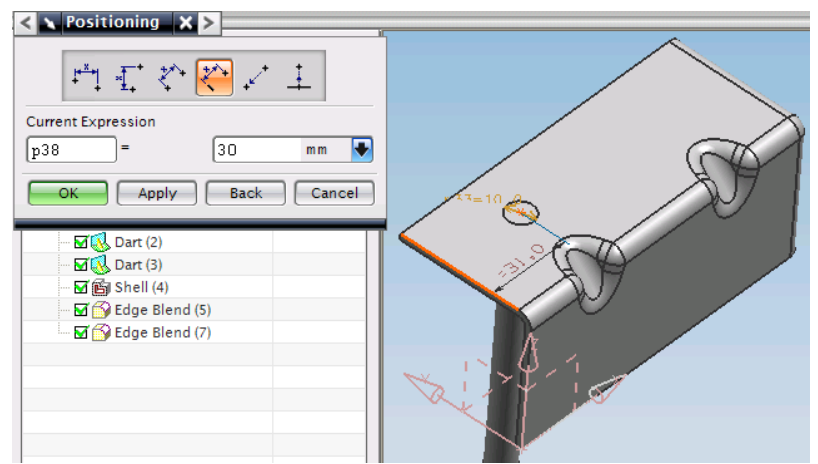

Figure 12 - First edge used to place the hole

Then click the edge shown below and then type $\mathbf{3 0}$ in the box shown then click Apply.

Then click the top edge shown then type in $\mathbf{2 0}$ in the box shown then click $\mathbf{O K}$. 

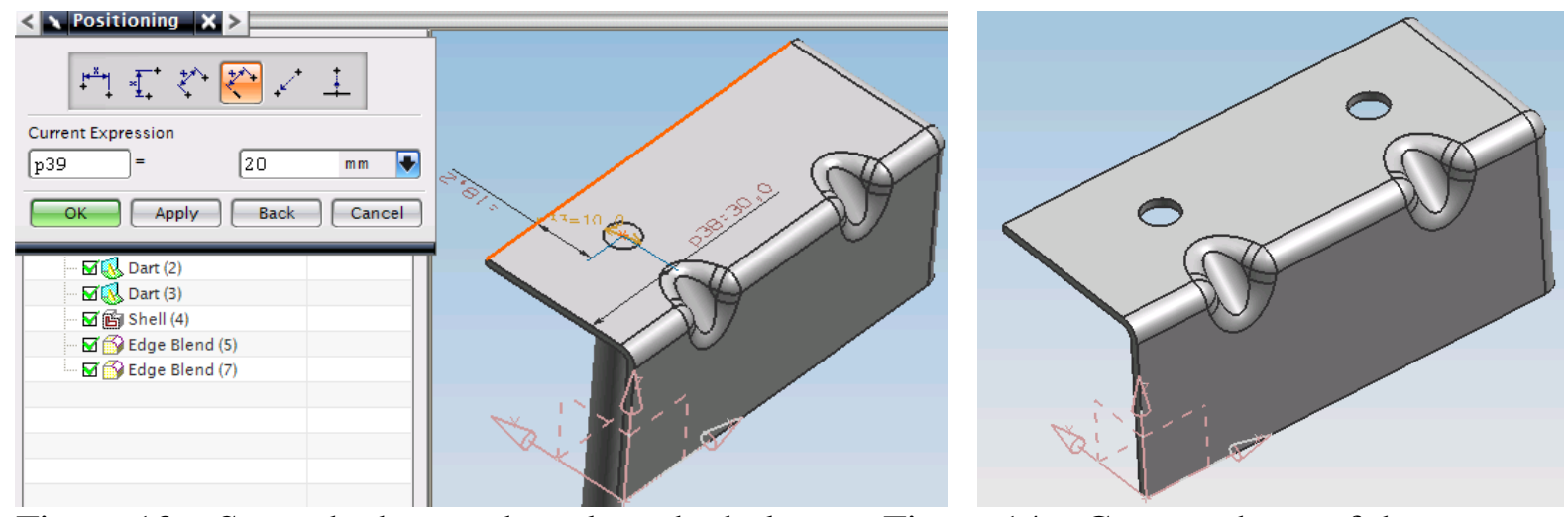

Figure 13 - Second edge used to place the hole

Figure 14 - Current shape of the component

Repeat the same process to create another hole that has a distance of $\mathbf{9 0}$ from the first edge and 20 from the second edge so that the part looks like the following picture.

9. Remove Lower Edge - Go to Insert then Sketch then click the face shown below then click $\mathbf{O K}$.

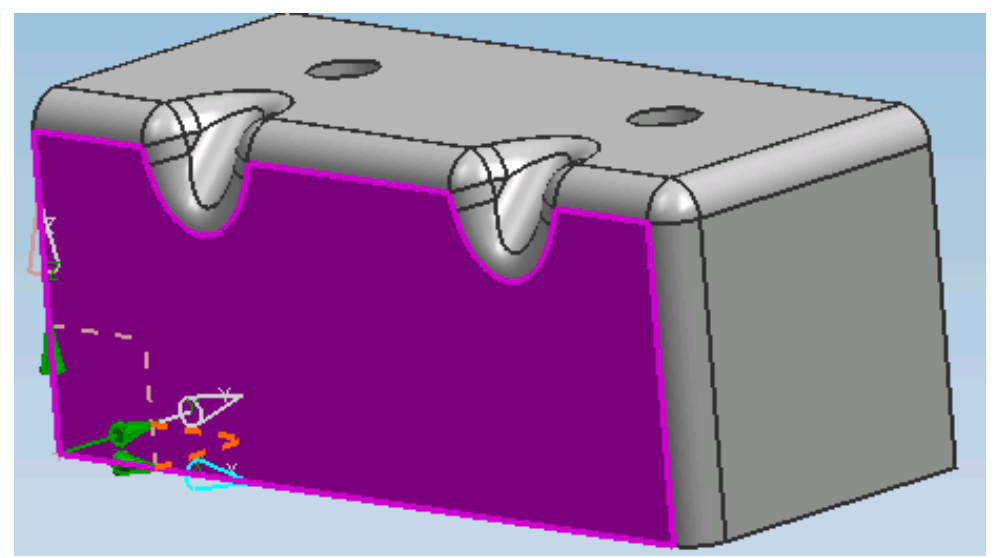

Figure 15 - Face used to create the sketch

Go to Insert then Rectangle to create a rectangle that is approximately the same size as shown. Make sure the right side and bottom of the rectangle are outside of the part as shown. Then click the Finish Sketch icon.

Go to Insert then Design Feature then Extrude then click the sketch that was just created. Then drag the ends of the arrow that appears so that the ends of the see thru box are outside of the part as shown and then click $\mathbf{O K}$.

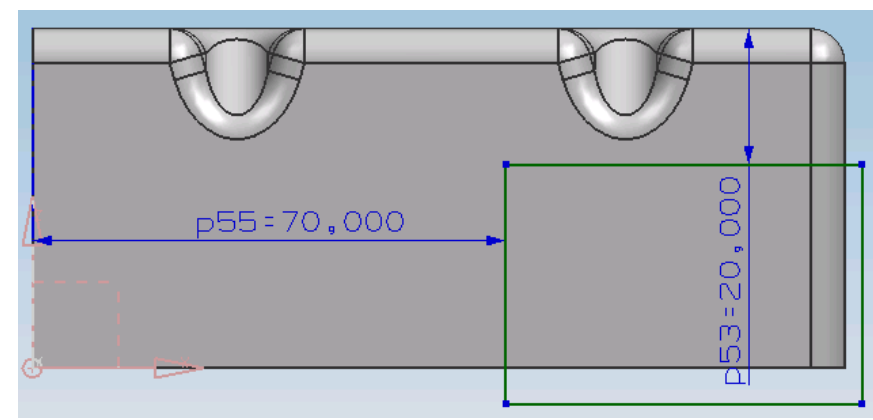

Figure 16 - The sketch that is created on the face 


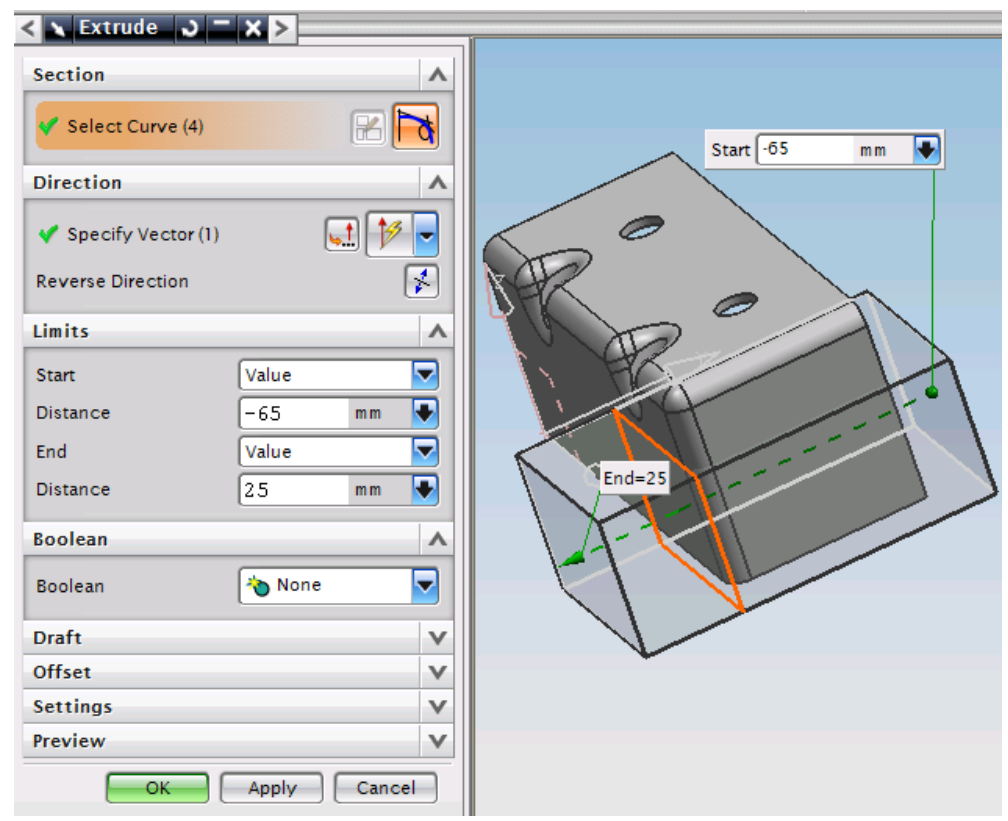

Figure 17 - Extruded box

Then go to Insert then Combine Bodies then Subtract then click the original part then click the solid box that was just created then click $\mathbf{O K}$. The part should now look like the picture shown below.

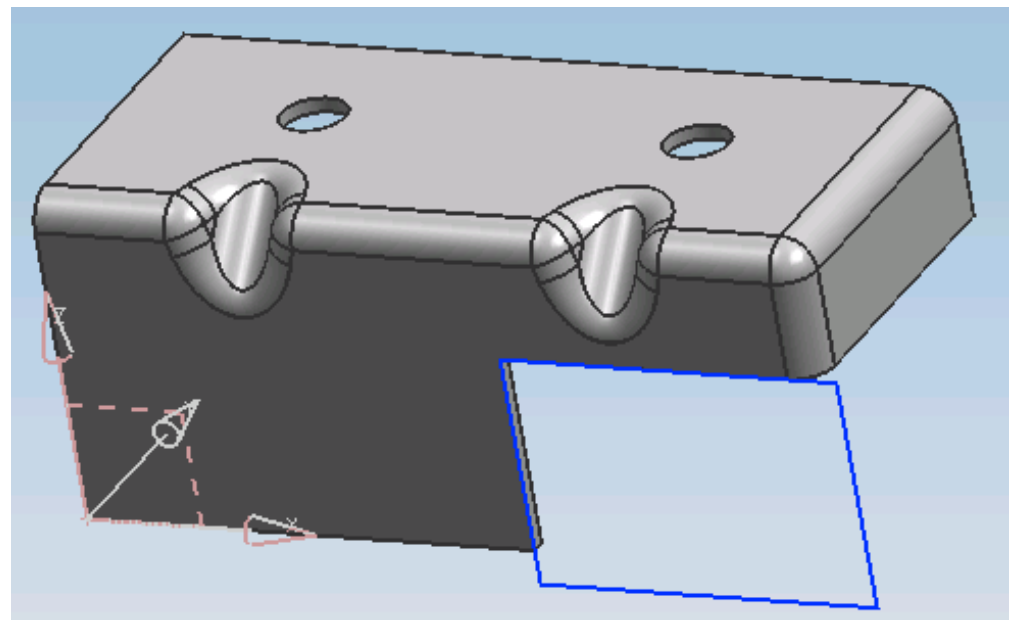

Figure 18 - Subtracted corner

The blue sketch can be hidden by hitting the keys ctrl-w and then expanding the Geomtry tree and then clicking the minus sign next to Sketches.

10. Create Radii at the Edges - Click the Edge Blend icon on the Feature Operation toolbar and then enter $\mathbf{1 0}$ for the Radius $\mathbf{1}$ value then click the five highlighted edges shown below then click $\mathbf{O K}$. 


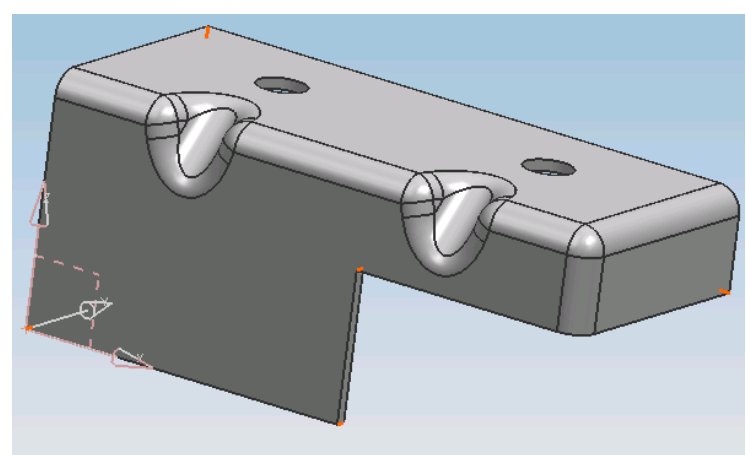

Figure 19 - Edges that need to be selected

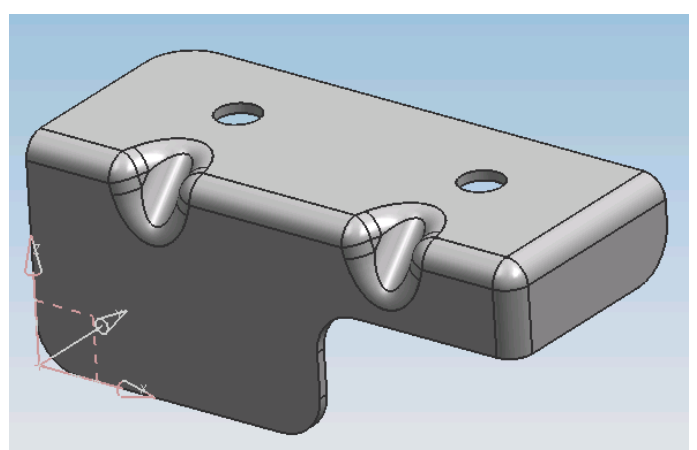

Figure 20 - Final shape of the component

The part should now look like the picture shown in Figure 20.

11. Create an .igs file - Save the part. Then go to File then Export then IGES then click the yellow folder icon to name it something and save it to a location that you can remember. This creates a .igs file that can be imported into HyperMesh for the simulation. An .igs file is a standard file that describes the geometry of the parts it was made from so that the geometry that was created can be imported into different types of software programs.

\section{Meshing}

1. Open HyperMesh - Start HyperMesh by going to the Start button then All Programs then Altair HyperWorks 9.0 then HyperMesh. A User Profiles window should pop up. If the User Profiles window doesn't pop up go to Preferences then User Profiles. Under the Application drop down list select Manufacturing Solutions then select HyperForm then select 1Step from the drop down list then click $\mathbf{O K}$.

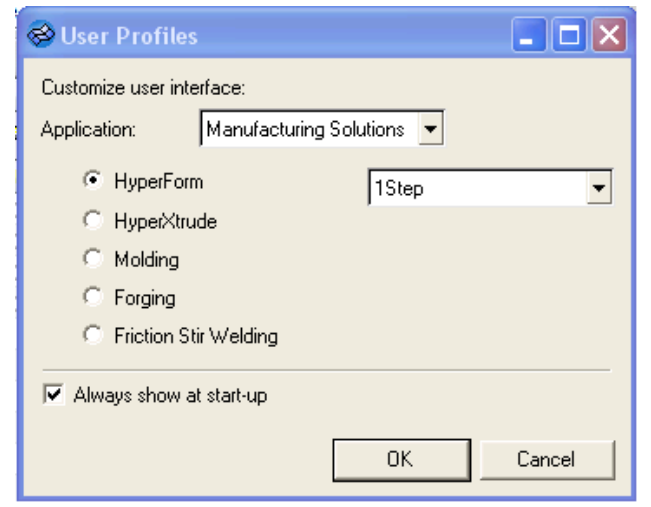

Figure 21 - User profile window

2. Import the .igs File - Go to File then Import then for the Import Type choose Geometry then for the File type choose Auto Detect then click the yellow folder icon and browse to where the igs file is located that contains the geometry of the part from the instrument panel and click Open then click Apply. 
3. Shade the Geometry - Click the icon to shade the geometry. By holding down the ctrl key on the key board and left clicking on the screen and holding down the left mouse button and moving the mouse around the part can be moved around. To change the origin of rotation hold down the ctrl key and left click somewhere on the part and let go.

4. Create a Midsurface - Go to Geometry then AutoCleanup then click the green edit parameters box and then the following window will pop up. Change the Target element size: to a value of $\mathbf{6}$ and then add a check mark in the box next to Extract midsurfaces and then uncheck the box next to Sheet metal only. Leave everything else as the default values as shown below and then click $\mathbf{O K}$.

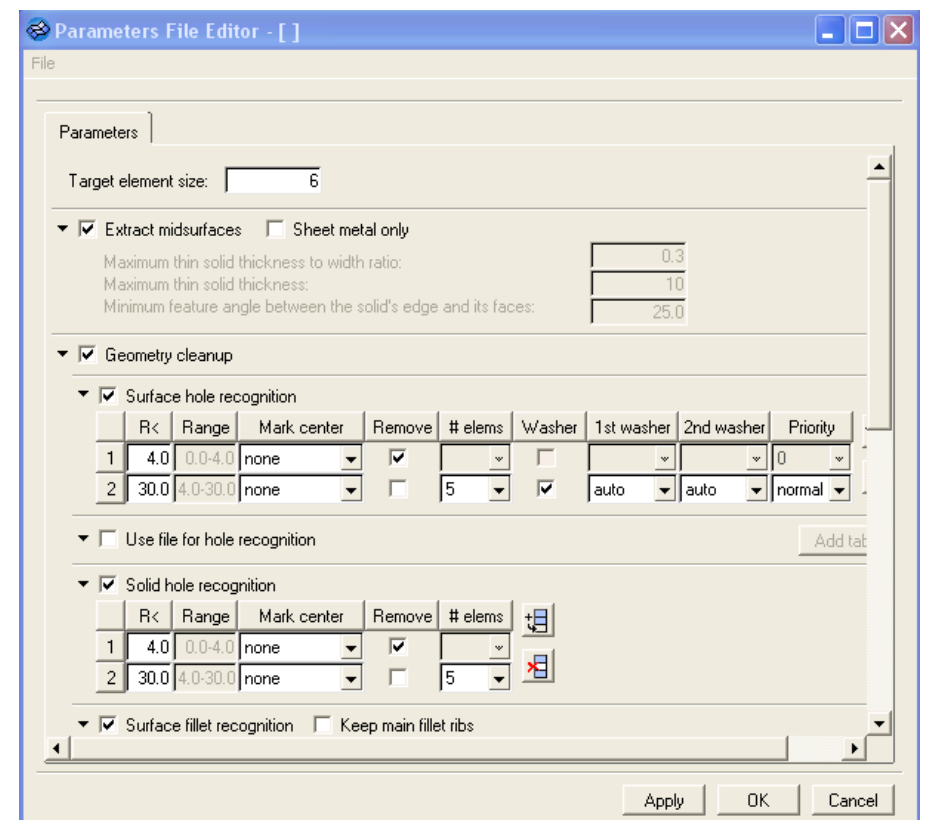

Figure 22 - Midsurface parameters

Click the green edit criteria box then change the Target element size: to a value of 6 then change the Min Size value to $\mathbf{3}$ and leave everything else as their default values as shown below and then click $\mathbf{O K}$.

Click the yellow surfs button and then click all then click autocleanup. The cleanup should take a few seconds and then click return. The midsurface should look similar to the picture below.

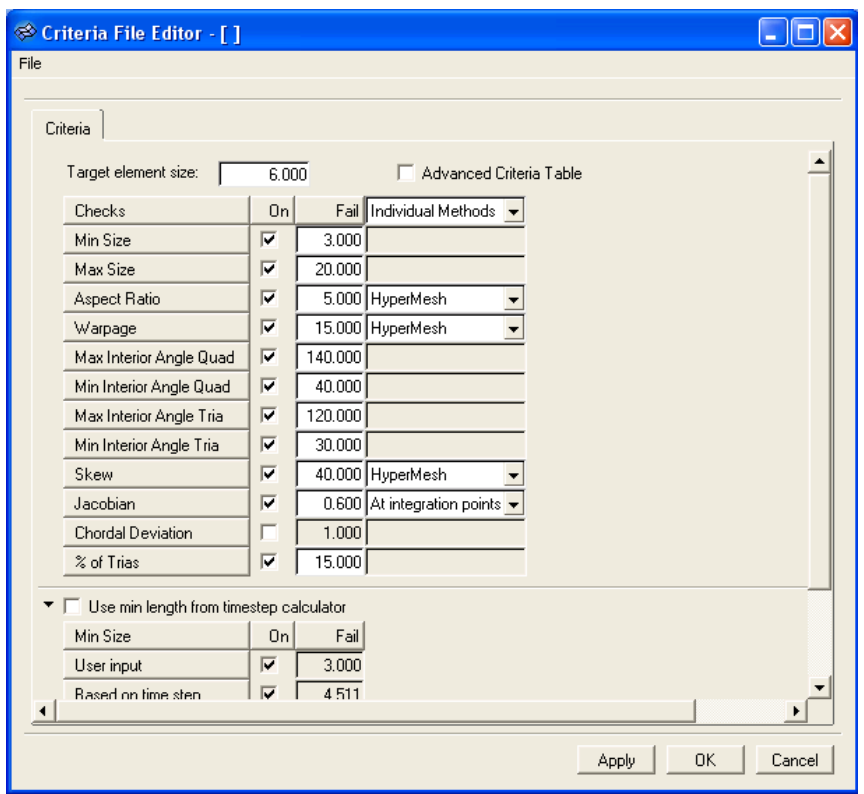




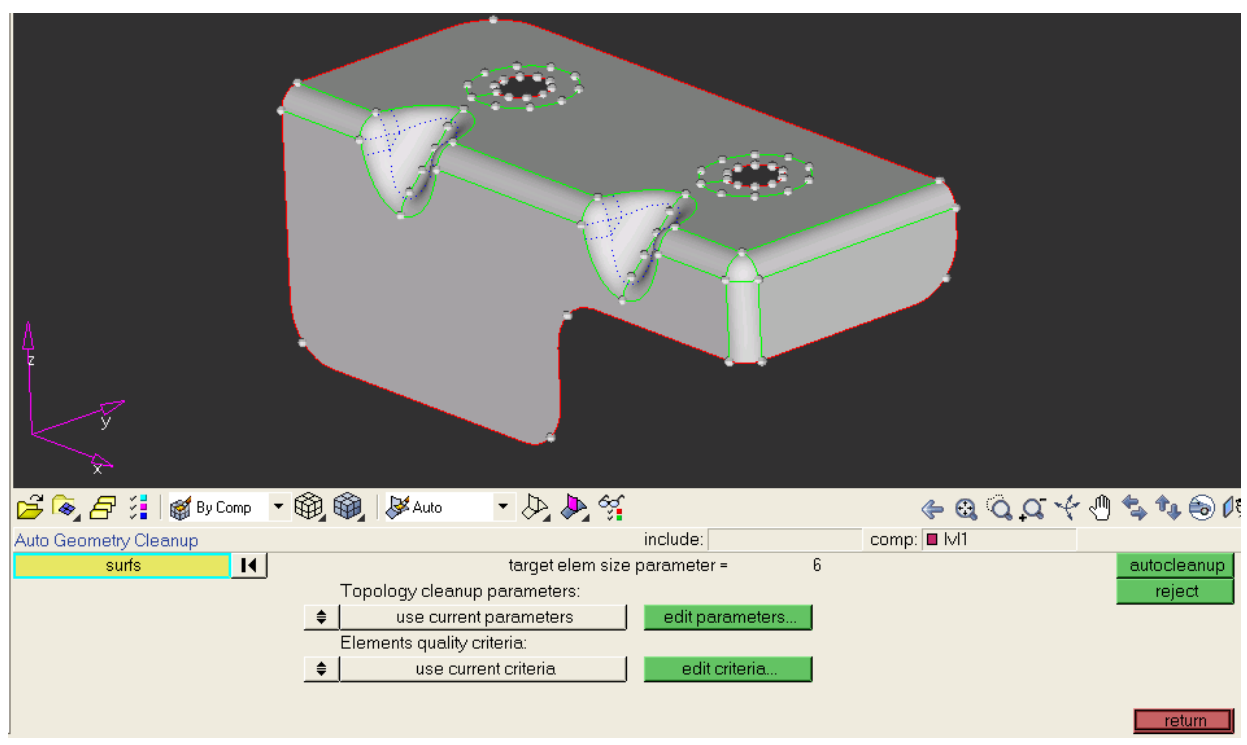

Figure 24 - Extracted midsurface

5. Mesh the Part - Click the F12 key on the keyboard (if nothing happens when you hit the shortcut function keys make sure there is no red return box in the bottom right corner of the screen and also click somewhere on the screen next to the model) then change the element size to a value of $\mathbf{6}$ then click the first drop down box and select surfs then click the yellow surfs box then click all then mesh then click return. Click the 1 icon in the lower middle portion of the screen to shade the mesh. This creates rectangular and triangular shell elements on the midsurface of the part. Shell elements are used as opposed to brick elements because they should be more accurate for thin sheet metal parts.

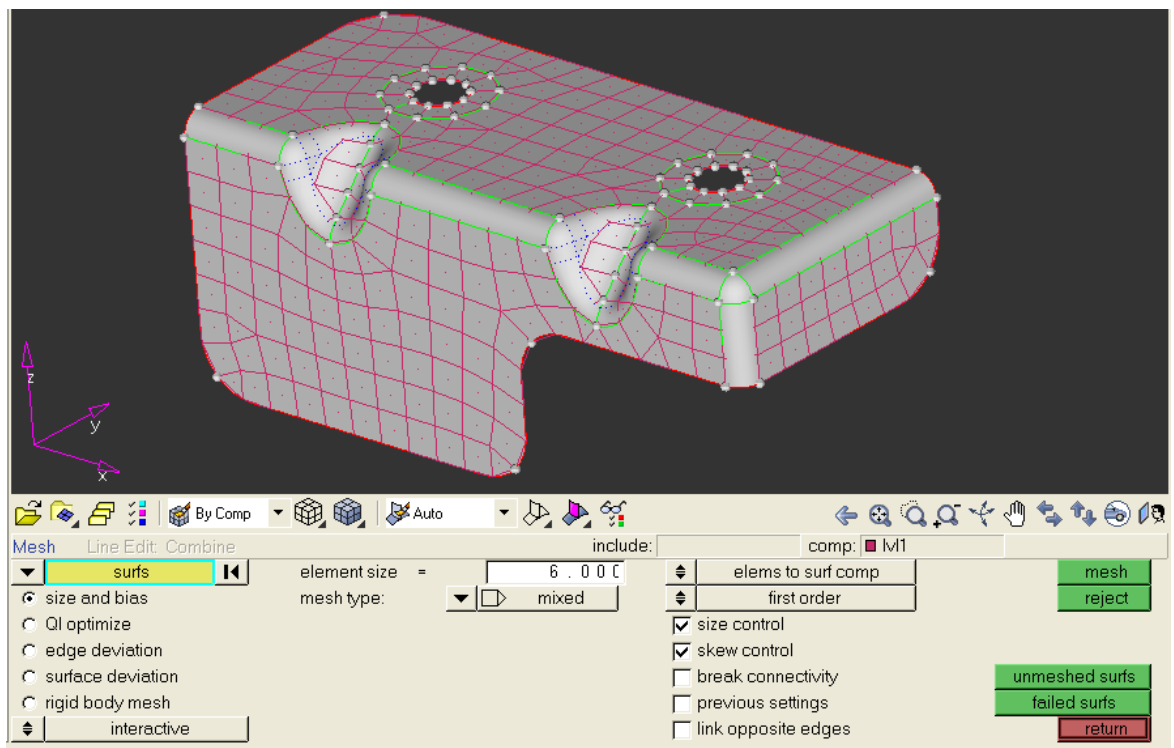

Figure 25 - Meshed component 
6. Turn Off the Geometry - Hit the F5 key on the keyboard (if nothing happens when you hit the shortcut function keys make sure there is no red return box in the bottom right corner of the screen and also click somewhere on the screen next to the model) and then click the drop down box and choose surfs then click the yellow surfs box and then choose all then click mask.

7. Cleanup the Mesh - Hit the F6 key on the keyboard then click the cleanup button then select displayed elements from the drop down box then click cleanup.

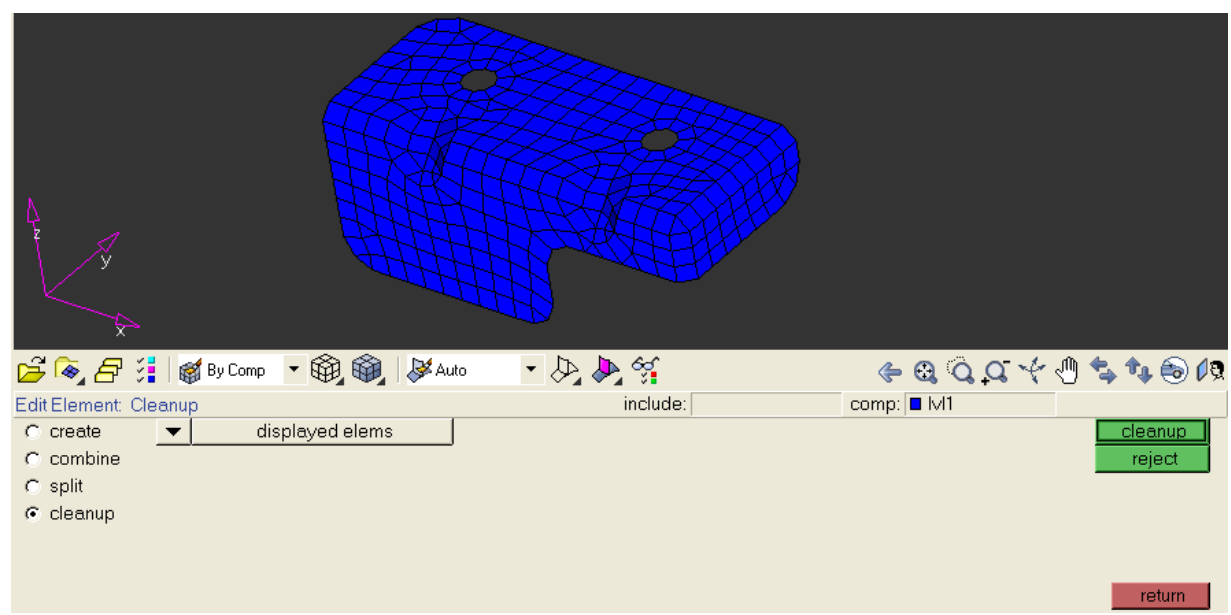

Figure 26 - Cleanup all displayed elements

Then click the set ranges box and enter the numbers as shown below.

$\sqrt{\checkmark}$ quad maxangle
tria maxangle
$\sqrt{\checkmark}$ warpage
$\sqrt{\checkmark}$ jacobian
$\sqrt{\checkmark}$ skew
$\sqrt{\checkmark}$ length

\begin{tabular}{r|r}
$>$ & 125.000 \\
$>$ & 100.000 \\
$>$ & 10.000 \\
$>$ & 0.700 \\
$>$ & 30.000 \\
$>$ & 3.100
\end{tabular}

\begin{tabular}{r|r} 
& \multicolumn{1}{c}{ unacceptable } \\
\cline { 2 - 2 } & \multicolumn{1}{c}{135.000} \\
$>$ & 120.000 \\
$>$ & 15.000 \\
$>$ & 0.600 \\
$>$ & 45.000 \\
\hline & 3.000
\end{tabular}

Figure 27 - Cleanup parameters

Check the boxes next to skew and length and leave the other boxes checked. The part should look similar to what is shown below.

Figure 28 - Red elements that need to be cleaned up

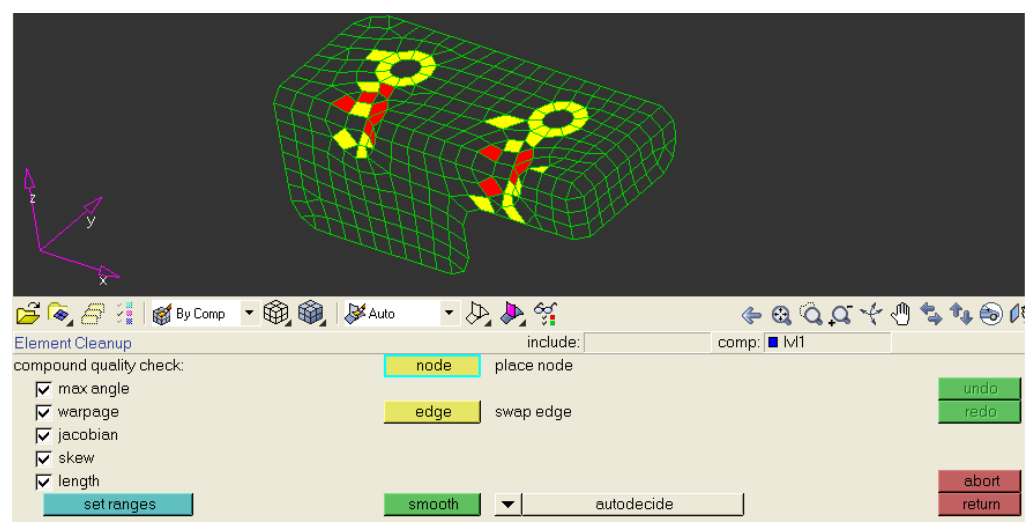


The red elements are the elements that are badly deformed and could lead to nonrealistic results during the simulation. These red elements fail the element checking criteria based off of the ranges that were set above, which are reasonable for this sheet metal part that is $2.2 \mathrm{~mm}$ thick. By clicking on the nodes and dragging them small distances (i.e. less than about $1.0 \mathrm{~mm}$ ) to different locations the red elements can be corrected. If the nodes have to be moved a relatively large distance leave them where they are so that the part doesn't get badly distorted. After moving a node it can be moved back to its original position by clicking undo. If all the red elements cannot be corrected hit the F10 key on the keyboard then click the 2-d button and type $\mathbf{5}$ next to warpage then click the warpage box, then the elements that are badly warped will be highlighted, then click save failed.

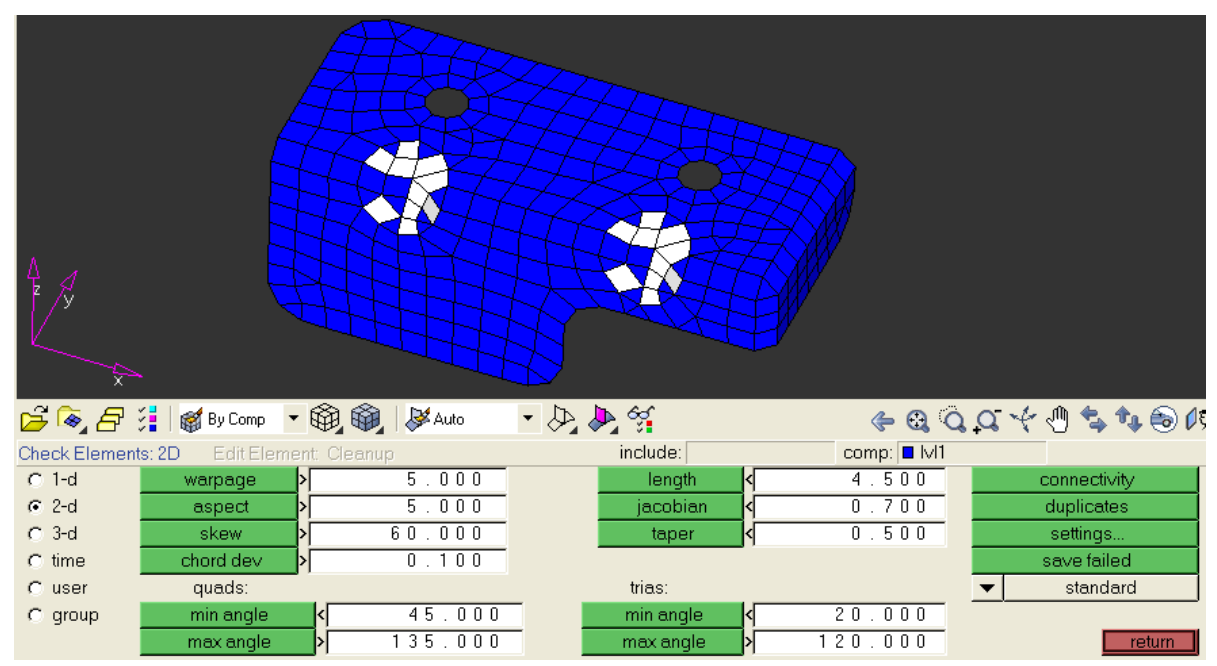

Figure 29 - Highlighted elements to be split

Then go to Mesh then Edit then Elements then Split Elements then click the plate elements button then select the drop down box $\boldsymbol{\nabla}$ and pick divide quads then click the yellow elems box and select retrieve then click split then click return.

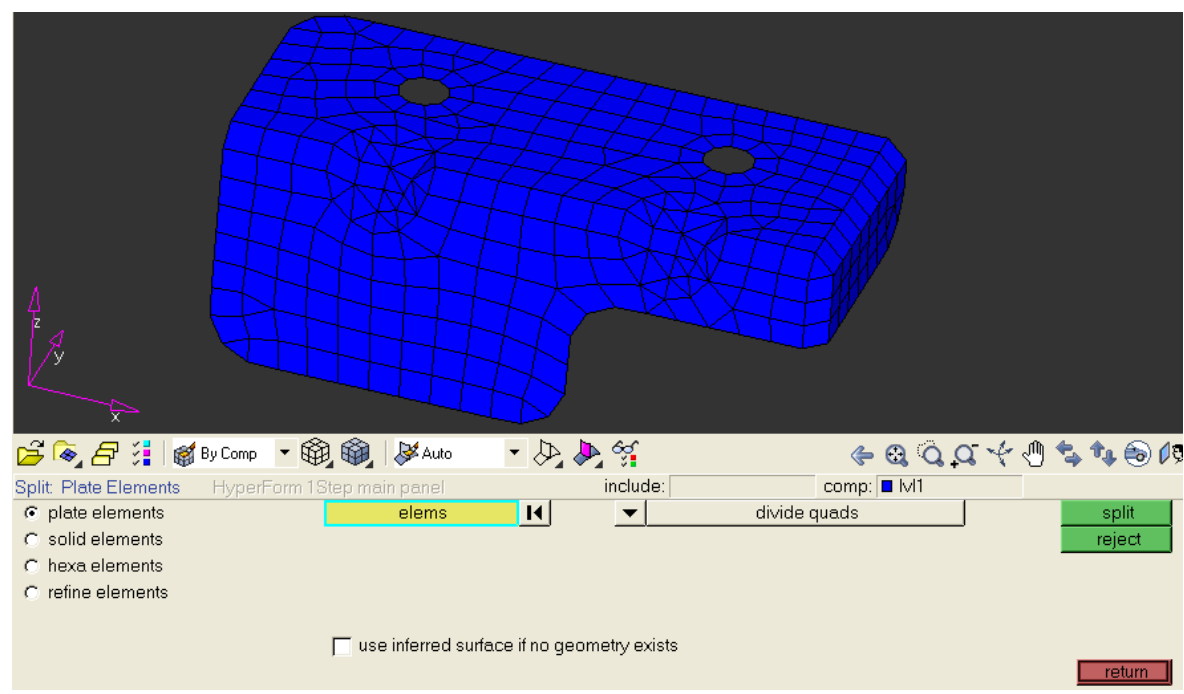

Figure 30 - Elements after being split 
Try to cleanup the remaining failed elements again by hitting the $\mathbf{F 6}$ key. The simulation will still run if there are failed elements, unless they are severely distorted. Results of the simulation will be closer to the actual physical results of the stamping process if the quality of the mesh is good. It should be mentioned that triangular elements tend to stiffen the part which leads to erroneous results as well, therefore the less triangular elements the better.

\section{Simulate the Stamping Process}

1. Orient the Part - For the stamping simulation it is assumed that the undeformed blank that the part is made from lies along the XY plane and that the die travels along the negative $\mathrm{Z}$ axis to stamp the part into shape. When the part was created in UGS NX 5.0 the part should have been oriented the correct way for the stamping simulation as shown here.

If this is not the orientation of the part it can be reoriented. Click the Utility tab in the upper left portion of the screen and then click the 1Step box at the lower left portion of the screen then click Autotip then click the purple rotate box.

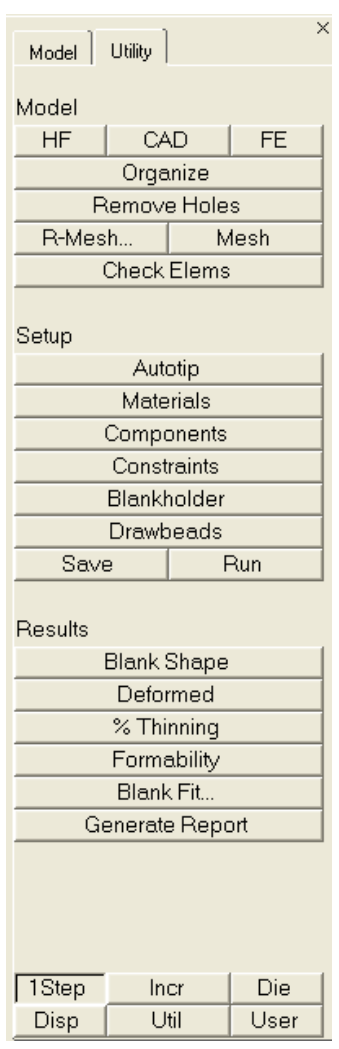

Figure 31 - Correct orientation of component to the coordinate axes

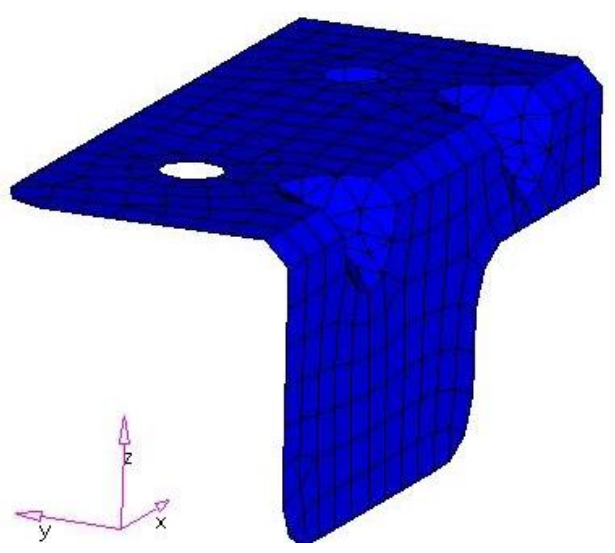

Click the comps box from the drop down box on the left side of the screen. Highlight the comps box by clicking $\mathbf{I U}$ next to it then click the meshed component on the screen. Select which axis you want to rotate the meshed component about by selecting it from the other drop down box. Highlight the purple B box by clicking $\mathbf{I U}$ next to it then click a node on the meshed component to indicate the origin the part will be rotated about. Specify the angle that you wish to rotate the component by typing it into the angle box then click the rotate + or rotate - box to reorient the meshed component. Repeat for theother two axes if necessary. Click return.

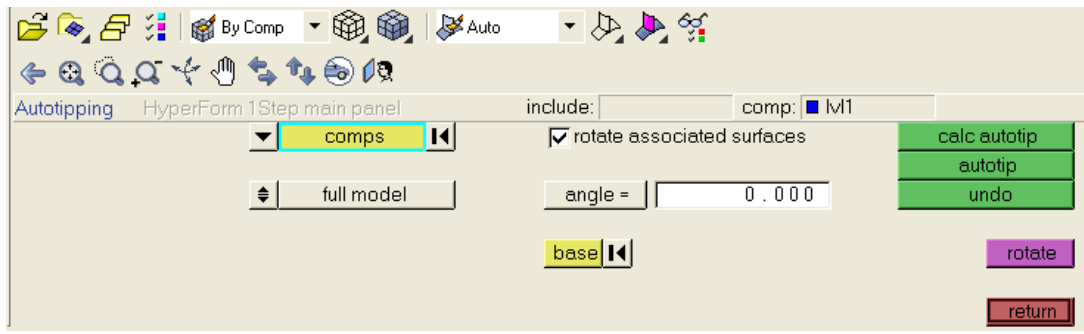

Figure 32 - Autotip dialoge window 


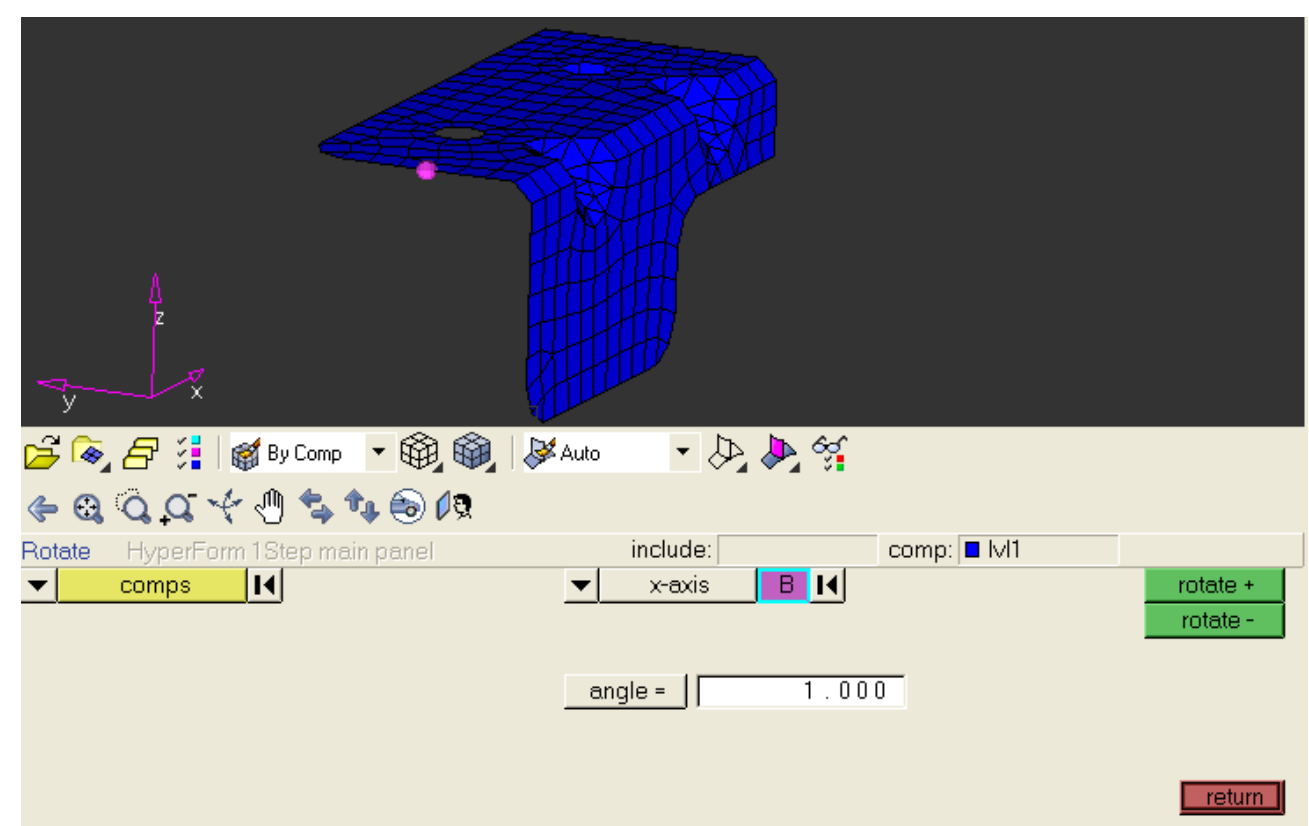

Figure 33 - Point where component will be rotated about

Select comps from the drop down box then highlight comps by clicking 14 next to it then click the meshed component on the screen and then click calc autotip then click return.

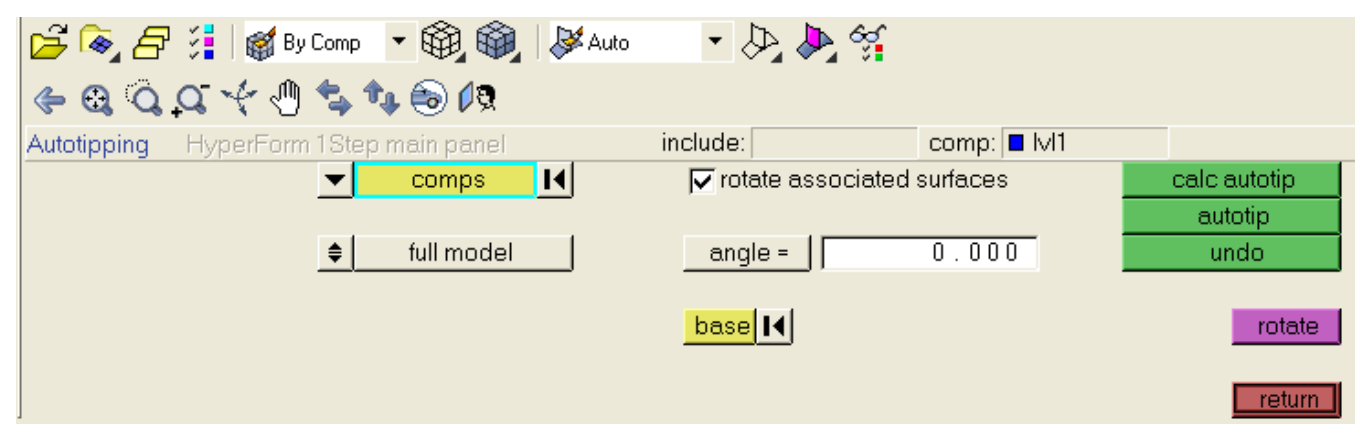

Figure 34 - Autotip dialogue window

You can tell if the part is oriented correctly later when the simulation is ran because if it isn't an undercut error will occur and the orientation will need to be adjusted again. The side of the part that is being undercut will be highlighted when the simulation is ran to indicate where the error is.

2. Create the Material Collector - On the left side of the screen click Material then click the create button then rename the material and type in the vales as shown below (which is for AISI 1008 steel) and then click the create box or update if there is already a material collector with this name. 


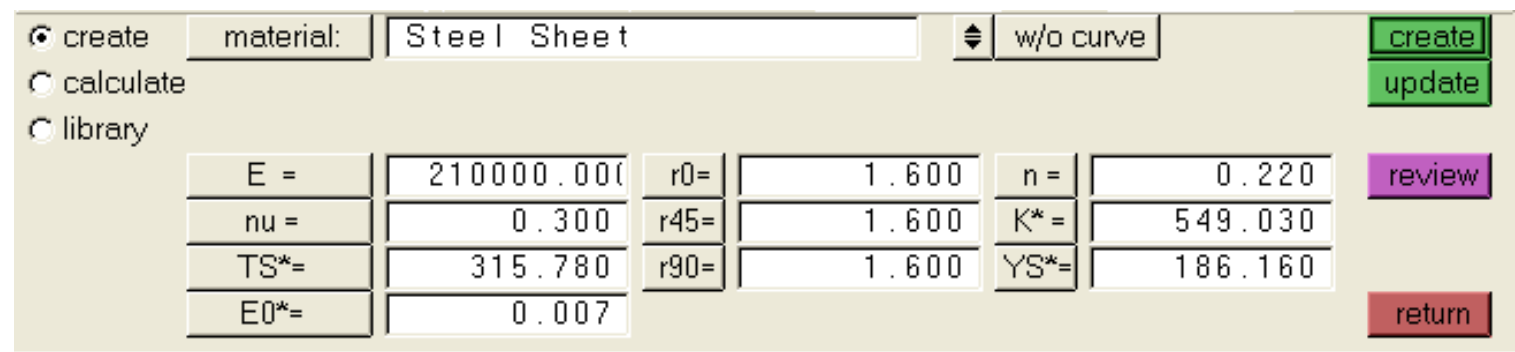

Figure 35 - Material parameters

3. Create the Component Collector - Click Components on the left side of the screen then click the component: box (you may need to click it twice) then click the box with the name of the component (there should only be one and it may be named different than lv11) then click the material box and click the material collector that was created earlier then type in $\mathbf{2 . 2}$ for the thickness then click update. (do not click create since a component should already exists)

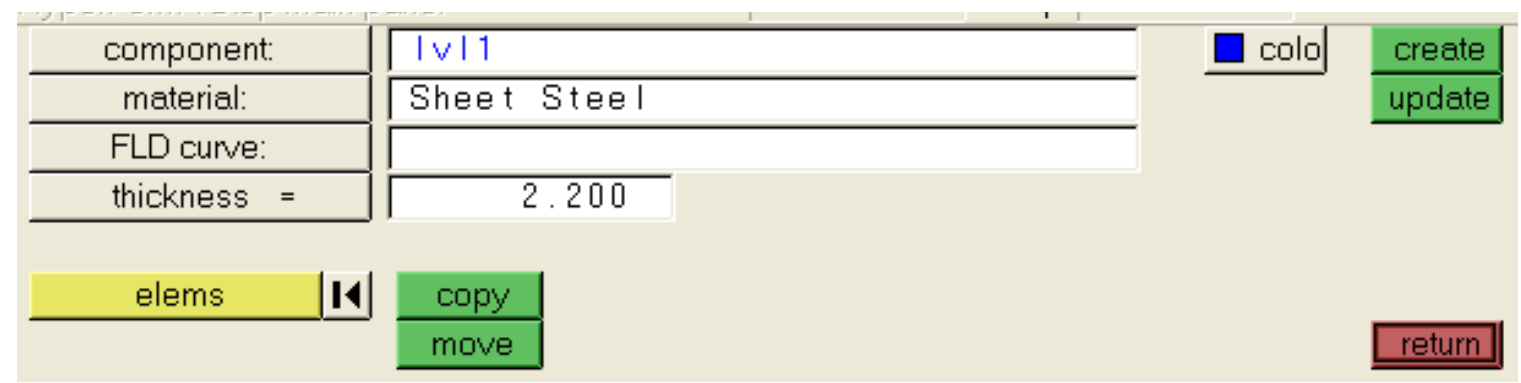

Figure 36 - Component collector dialogue

4. Create Constraints - Click Constraints on the left side of the screen then click two nodes in the approximate location as shown (the nodes need to be on elements that lie along the XY plane) then click update.

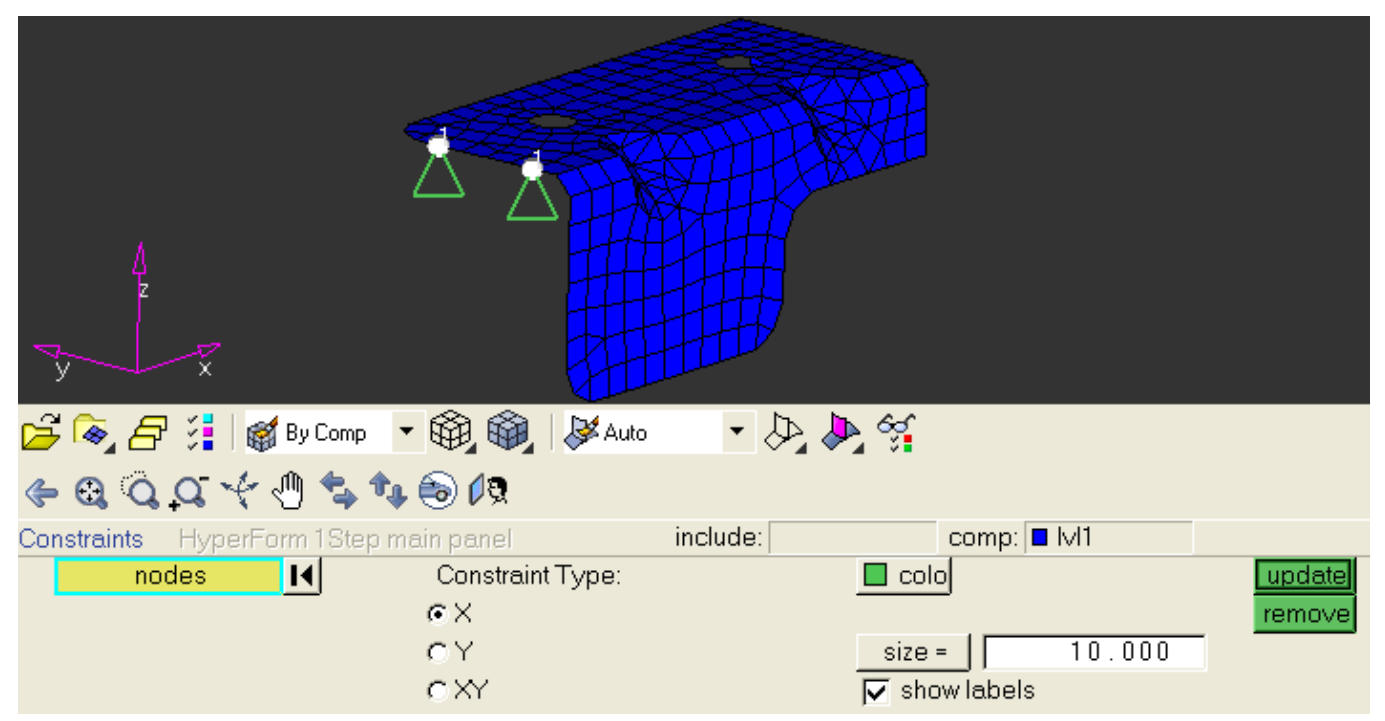

Figure 37 - Points where the component is constrained 
5. Create the Blankholder - Click Blankholder on the left side of the screen then name it Blank and type in the values as shown below, then click the yellow elems box and then click on plane then select three nodes on the blank surface (shown in light blue below) to define the plane that contains the elements to be selected then click create. The blankholder is used to define the plane that is perpendicular to the path that the punch travels to create the part.

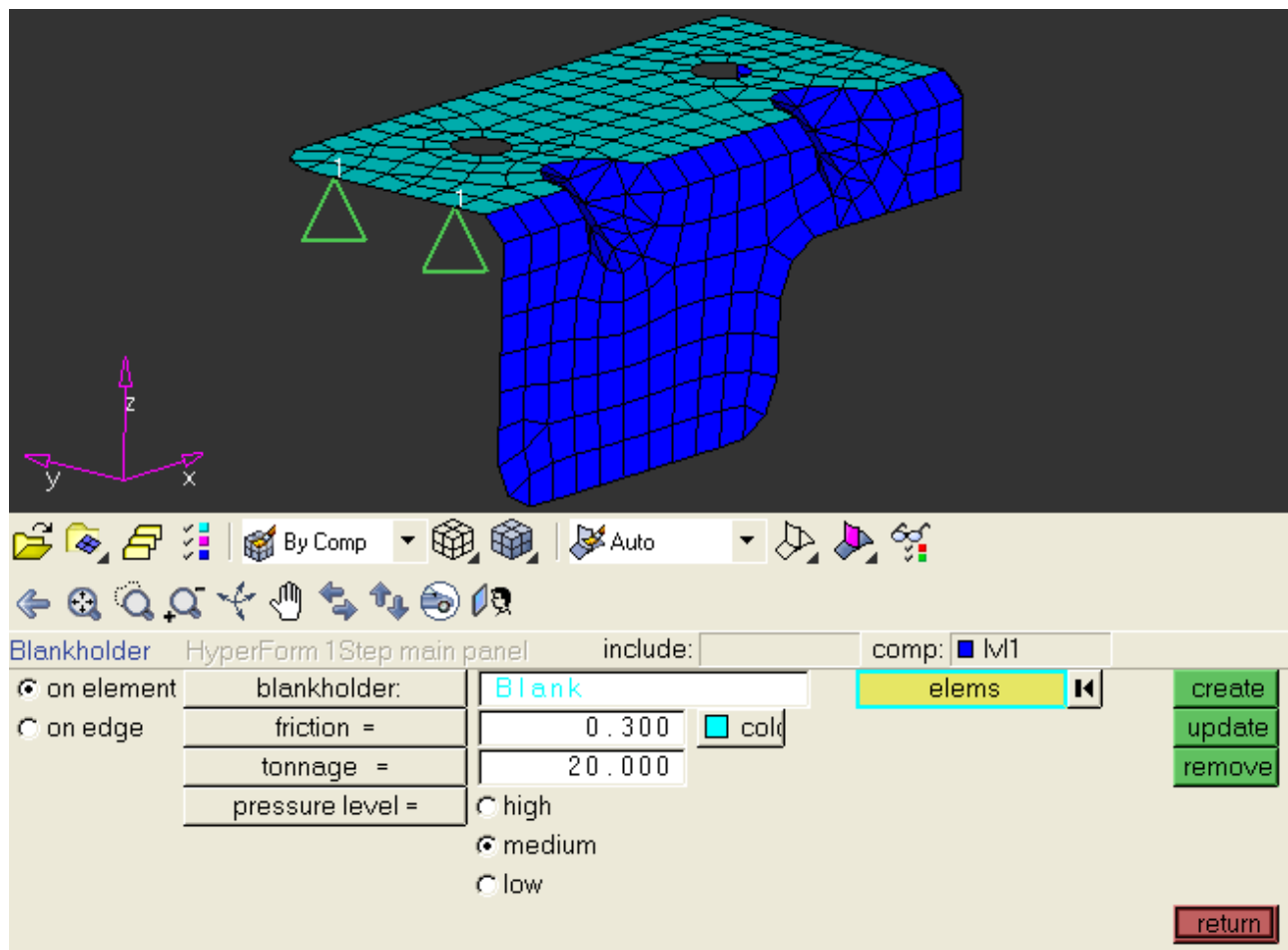

Figure 38 - Blankholder surface

6. Save and Run the Simulation - Click Save on the left side of the screen then click save as then save the file as a Hyperform Binary File (*.hf*) to a separate folder called Simulation someplace you can remember.

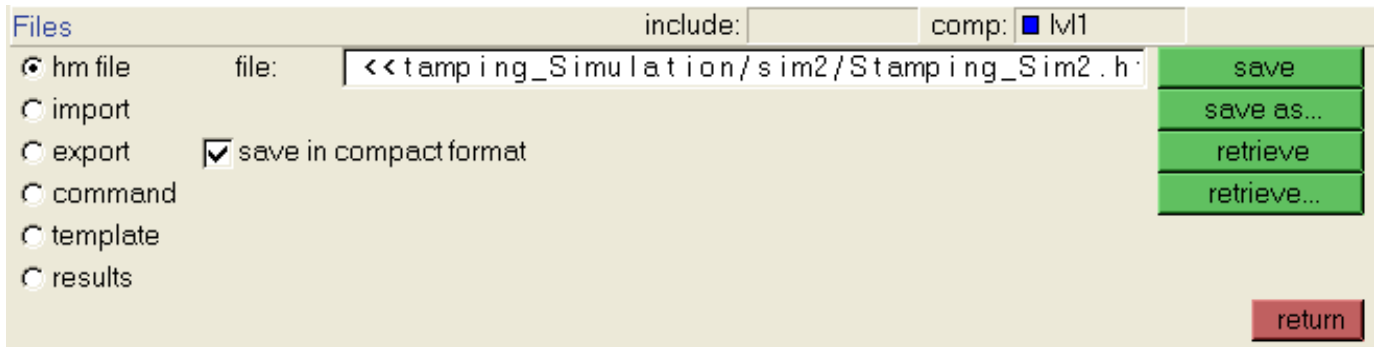

Figure 39 - Window used to save the component

Click Run on the left side of the screen and then click run analysis. 


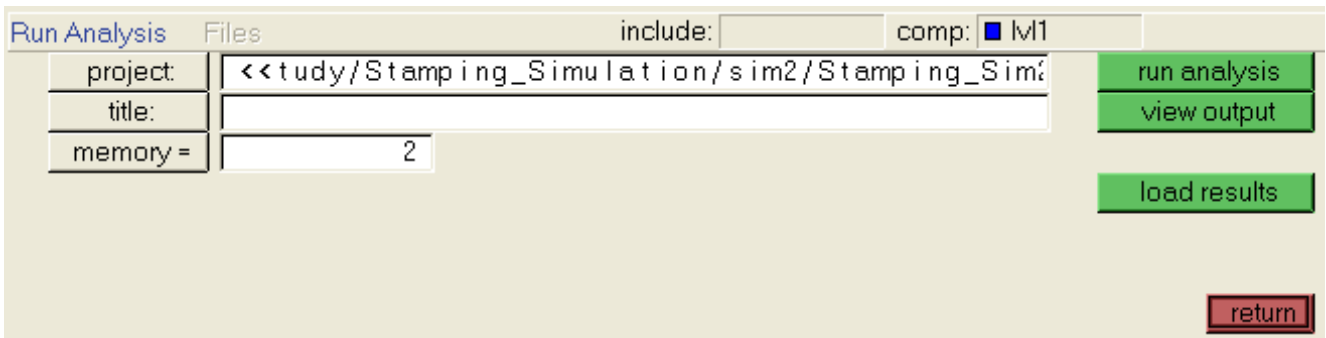

Figure 40 - Window used to run the simulation

A DOS window should pop up and after a few seconds should say that the processing is complete. The simulation is ran in the Simulation folder that was created earlier and all the results are copied to this folder.

\section{View the Results}

1. Load the Results - Go to File then Load then Results then browse to where the Simulation folder is and open the res file then click Open.

2. View Thinning - Click \% Thinning on the left side of the screen and then the results should look similar to what is shown below. The results show that the maximum $\%$ thinning is $20 \%$ at the corner shown in red. This is usually the value where splits in sheet metal start to occur (depending on the type of material used) from too much thinning of the material. If this was an issue the lower edge of the part could be raised which should lower the $\%$ thinning to correct the problem or the initial thickness of the part could be increased as well. This \% thinning is the percentage that the thickness of the sheet metal will be reduced from its original thickness during the stamping process.

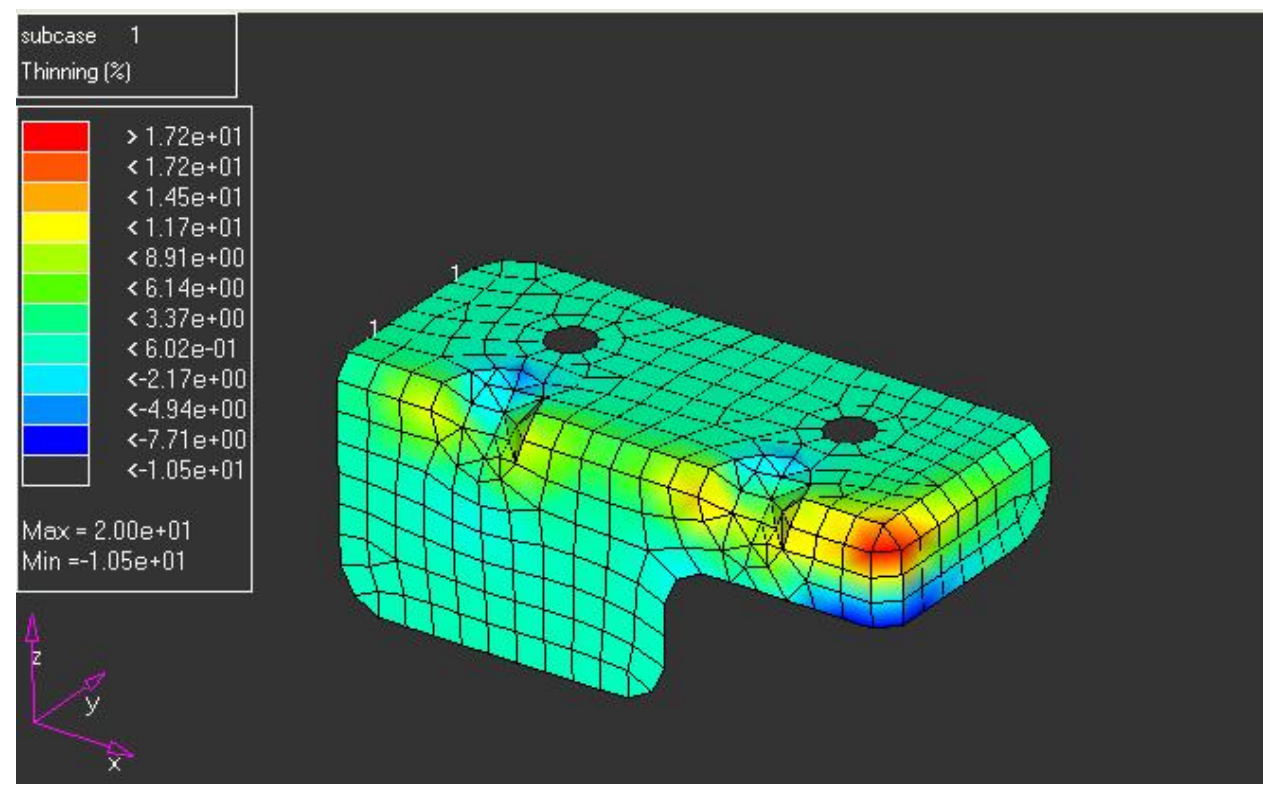

Figure 41 - Thinning results of the component 
3. View Formability - Click Formability on the left side of the screen and then the results should look similar to what is shown below. Formability tells you whether or not the part that is being analyzed will have any problems during the manufacturing process. There are no red Failure zones shown on the meshed part and all of the corresponding points from each element that are plotted on the FLD curve in the upper right corner of the screen are below the yellow marginal line. This indicates that if the material used to make the part has properties that are close to the ones that were specified for the analysis then the part should not see any splits during the manufacturing process. If any points are plotted above the yellow marginal line it indicates that splits may occur and if they fall above the red line then splits are predicted to occur and the part should be redesigned.

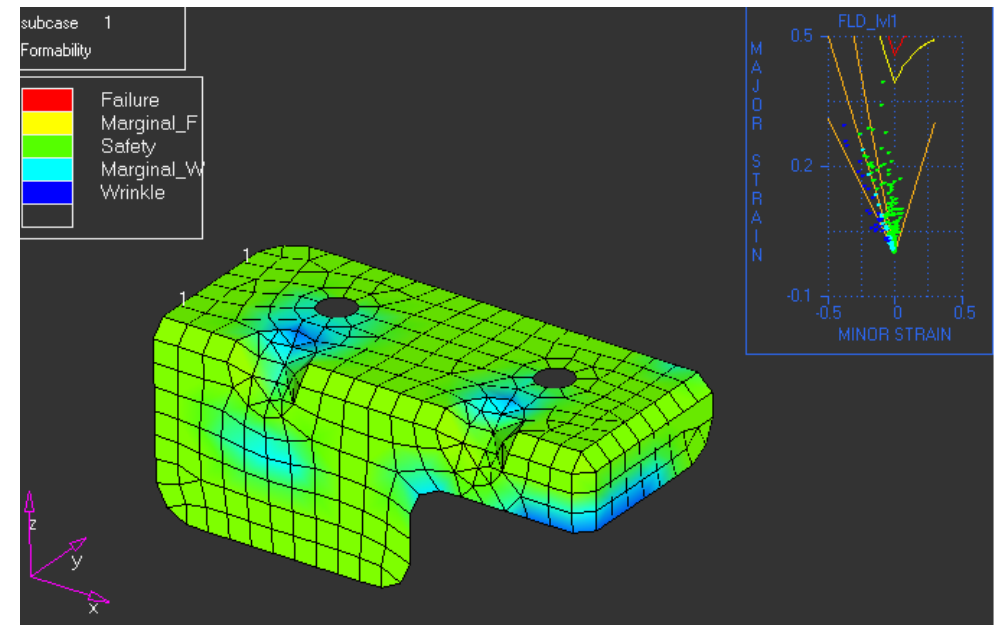

Figure 42 - Forming limit diagram

\section{Design of Experiments ${ }^{3-5}$}

Since many simulations can be performed on a stamping process to analyze several designs, a DOE (design of experiments) is used in this paper to determine which factors and interactions play the most important role in the forming process and hence effect the thinning. The same stamping simulation is performed while adjusting different factors like friction, material thickness, and tonnage for each simulation to determine which factors influence the formability (e.g. \% thinning) of the part. One of the easiest DOE's to perform is the 2k Factorial Design. The 2 represents the two levels (values) that each of the $\mathrm{k}$ factors can assume in the experiment. For this analysis there were originally four $(\mathrm{k}=4)$ factors in the process, the yield strength of the sheet metal, its thickness, the friction coefficient, and the tonnage of the press. For each complete trial or replication of the experiment all possible combinations of the levels of the factors are investigated. The number of runs can grow quickly though if more than four factors want to be investigated because a $2 \mathrm{k}$ factorial requires $2 \mathrm{k}$ combinations. With four factors this DOE required $24=16$ complete trials. The $2 \mathrm{k}$ factorial can be performed easily by setting up a spreadsheet that uses factor values and the thinning (response) of each complete trial as inputs and then the results (effects and interactions) are determined by using contrasts5. This can also easily be done using the regression data analysis tool in Excel. The results of the DOE can be used to find the optimum settings of the four factors to minimize the percent thinning (the 
response) of one of the corners of the part. Table 1 shows the factor values that were used in the analysis.

Table 1 - Factor level used in the DOE Studies

\begin{tabular}{|c|c|c|c|c|}
\hline $\begin{array}{c}\text { Factor } \\
\text { Level }\end{array}$ & $\begin{array}{c}\text { Yield } \\
\text { Strength } \\
(\mathrm{Mpa})\end{array}$ & $\begin{array}{c}\text { Thickness } \\
(\mathrm{mm})\end{array}$ & Friction & $\begin{array}{c}\text { Tonnage } \\
\text { (Tons) }\end{array}$ \\
\hline-1 & 186 & 0.8 & 0.05 & 20 \\
\hline+1 & 500 & 3.2 & 0.70 & 80 \\
\hline
\end{tabular}

The results of the DOE experiments showed that the yield strength was insignificant and could be disregarded. Since the forming analysis showed that no splits should occur in the bracket the yield stress should not have any effect on the results though. The least significant of the remaining three factors was tonnage. Therefore, using only the two most significant factors a response surface plot of the \% thinning of the bracket could be produced and is shown below.

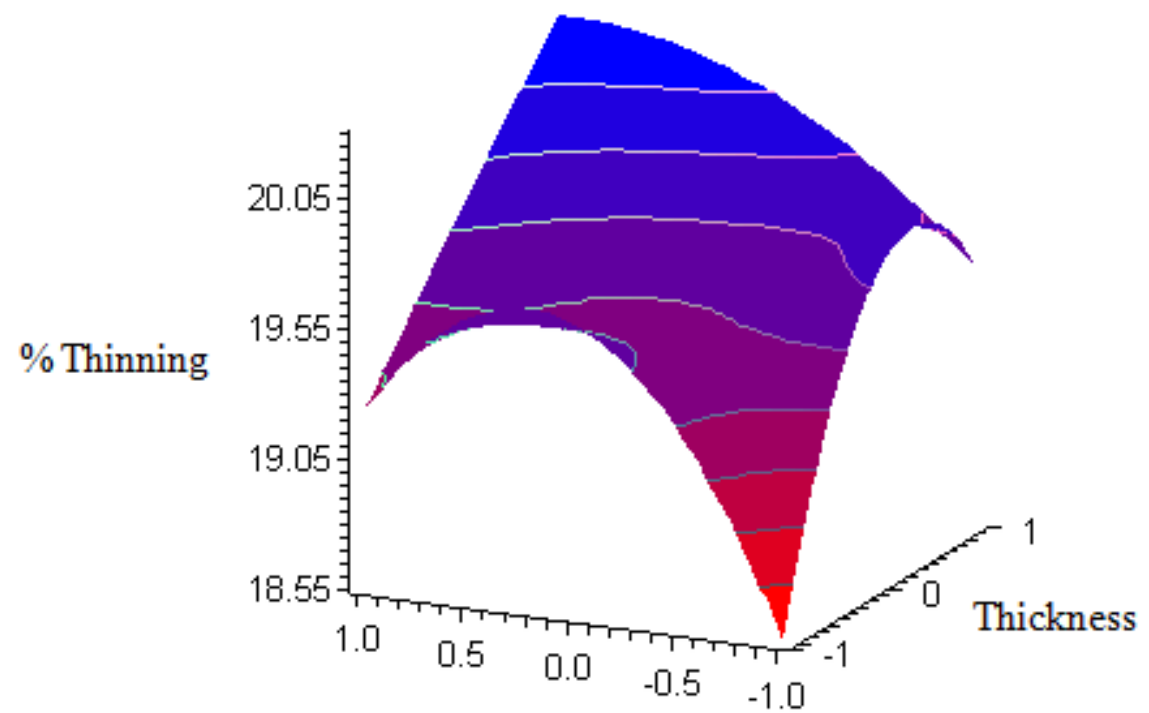

Friction

Figure 43 - Response surface plot of the component

The graph shows that to keep the \% thinning as low as possible, to reduce the chance that splits will occur, the friction and thickness should be kept as low as possible.

\section{Conclusions}

In this paper, a sample tutorial has been developed for use in the class room. This dealt with an integrated forming and preliminary DOE studies to understand the correlation between different forming parameters that affect successful forming of a part. To our knowledge, no such tutorial is available for use by the students in a class room set up. Students' response and course evaluation indicates that the tutorial was helpful for their easy understanding of the stamping simulation and analysis. More tutorials are needed to guide the student learners to work seamlessly between different software platforms. 


\section{Bibliography}

1. Introduction to UG-NX5 - Cast Tutorials.

2. HyperWorks by Altair Engineering.

3. Moaveni, Seed, "Finite Element Analysis," 3rd ed., Prentice-Hall, 2008

4. Kreyszig, E., "Advanced Engineering Mathematics", J. Wiley. 2006.

5. Jenning, Alan, "Matrix Computation for Engineers and Scientists", J. Wiley, 1988. 